\title{
INFÂNCIA E MÍDIAS DIGITAIS: HISTÓRIAS DE CRIANÇAS E ADOLESCENTES SOBRE SEUS COTIDIANOS
}

\author{
CHILDHOOD AND DIGITAL MEDIA: STORIES OF \\ CHILDREN AND ADOLESCENTS ABOUT \\ THEIR DAILY LIVES
}

Geusiane Miranda de Oliveira Tocantins ${ }^{1, *}$

Ingrid Dittrich Wiggers ${ }^{2}$ iD

\begin{abstract}
RESUMO: O artigo objetiva analisar apropriações de Tecnologias da Informação e Comunicação (TIC), com foco em mídias e tecnologias digitais, por crianças e adolescentes. Os dados foram constituídos por narrativas gráficas, em forma de histórias em quadrinhos produzidas pelos sujeitos, bem como por narrativas orais, em entrevistas episódicas. Participaram 21 estudantes da Escola Parque Anísio Teixeira. Os resultados indicam apropriações em convergência para uso individualizado das TIC, em crescente ocupação dos tempos e espaços do cotidiano. Sobretudo, crianças e adolescentes se distinguem, entre si, em suas apropriações.
\end{abstract}

Palavras-chave: TIC. Tecnologias digitais. Apropriação. Crianças e adolescentes. Cotidiano.

ABSTRACT: The article aims to analyze Information and Communication Technologies (ICT) appropriations by children and adolescents, with a focus on digital media and technologies. The data consisted of graphic narratives, in the form of comic books produced by the subjects, as well as oral narratives, in episodic interviews. Twenty-one students from the Anísio Teixeira Park School participated. The results indicate a convergence of appropriations for the individualized use of ICT, with an increasing occupation of time and space in daily life. Most importantly, children and adolescents are notably different in their appropriations.

Keywords: ICT. Digital technologies. Appropriation. Children and adolescents. Daily life.

\author{
1.Secretaria de Estado de Educação do Distrito Federal - Brasília (DF), Brasil. \\ 2.Universidade de Brasília - Brasília (DF), Brasil. \\ *Autora correspondente: geusiane@gmail.com \\ Número temático organizado por: Gilka Girardello, Adriana Hoffmann e Inês Vitorino Sampaio
}




\section{Introdução}

Os usos e as apropriações das Tecnologias da Informação e Comunicação (TIC) têm se evidenciado como fenômeno multifacetado, de análise complexa e em constante movimento, caracterizados por um campo teórico ainda não consolidado e que segue em desenvolvimento em várias vertentes. As frequentes mudanças tecnológicas e suas implicações na cultura e na vida das pessoas demandam novos olhares e investigações, mantendo em alerta os pesquisadores desse campo.

Os dados analisados por Silva e Mercado (2015), durante um amplo levantamento bibliográfico, indicam a atualidade das pesquisas com foco nos usos e nas apropriações das TIC. Os autores afirmam que o interesse das pesquisas sob a temática TIC se deslocou ao longo dos anos. No final do período analisado por eles, o deslocamento apontava para estudos sobre usos e apropriações das TIC, bem como para a formação de professores para e por meio da EAD. Compreendemos que esse deslocamento é um reflexo do avanço tecnológico em larga escala, principalmente no que diz respeito a mídias e tecnologias digitais. Portanto, os desafios e problemas de pesquisa se refazem constantemente.

A literatura aborda a apropriação das TIC como processo gradual, lento e complexo (BELLONI, 2005), composto por várias fases ou estágios. Para Sandholtz, Ringstaff e Dwyer (1997, p. 54), "a apropriação é o ponto em que um indivíduo passa a entender a tecnologia e a utilizá-la sem esforço"; ou seja, para os autores, a apropriação seria um marco nesse processo, evidenciada principalmente por mudanças que indicam o domínio pessoal dessas tecnologias.

A partir desse entendimento, apreendemos que a presença ou o uso das TIC na vida cotidiana não implica necessariamente apropriação, mas indica uma trajetória, um processo, que pode ou não culminar em apropriação. Apropriar-se de uma determinada tecnologia vai muito além de ter acesso a ela ou, simplesmente, utilizá-la em algumas situações. Nessa concepção, seria possível uma pessoa ter acesso, usar e não se apropriar. Por outro lado, a apropriação pode desdobrar-se em diversos modos, como em processos de reprodução ou ressignificação. Uma significativa discussão sobre o conceito de apropriação é apresentada por Batista (2018), cuja revisão de literatura internacional, a partir do uso de tal termo em português, inglês, francês e espanhol, objetivou sistematizar referências, priorizando os sentidos de apropriação em diferentes contextos.

Destarte, uma importante discussão nos campos teóricos nacional e internacional se volta às apropriações das TIC por crianças e adolescentes, bem como suas implicações na infância em mudança (BUCKINGHAM, 2007; BELLONI, 2010). O que as crianças e os adolescentes têm feito com essas tecnologias? Como se relacionam com elas e de que modo as inserem em sua vida cotidiana? Ainda são poucas as pesquisas que trazem a perspectiva das crianças e dos adolescentes para essa discussão. Em meio a discursos divergentes e, muitas vezes, polarizados, alguns autores defendem a necessidade de investigações a partir de informações produzidas empiricamente, buscando evidenciar a perspectiva desses atores sociais no encaminhamento para as tensões e os desafios que se apresentam (JAMES; PROUT, 1990; BELLONI, 2008).

Nesse sentido, este trabalho buscou compreender apropriações das TIC por meio de narrativas de crianças e adolescentes sobre seus cotidianos. No nosso entendimento, o termo TIC inclui todas as tecnologias da informação e comunicação, analógicas ou digitais. Todavia, nesse contexto, nosso olhar se voltou principalmente para as mídias e tecnologias digitais e os modos como permeiam os tempos e espaços de nossas vidas cotidianas. Buscamos, então, a perspectiva das crianças e dos adolescentes, para além dos limites da escola, na revelação do social, na "lógica da descoberta na qual a realidade social se insinua, conjectura, indicia”, como afirma Pais (2003, p. 32). 


\section{Trajetórias de Aproximação ao Cotidiano das Crianças e dos Adolescentes}

Nossa pesquisa desenvolveu-se por meio de um trabalho de campo com abordagem qualitativa e foi realizada na Escola Parque Anísio Teixeira (EPAT), situada na região administrativa da Ceilândia, Distrito Federal. A EPAT é a primeira escola parque no Distrito Federal a ser instituída fora dos limites do Plano Piloto. Foi inaugurada no segundo semestre de 2014 e estabelecida nas antigas instalações do Serviço Social da Indústria (SESI), que atualmente pertencem à Secretaria de Estado de Educação do Distrito Federal (SEEDF). Oferece 3.200 vagas para estudantes do $6^{\circ}$ ao $9^{\circ}$ ano do Ensino Fundamental de escolas públicas das regiões administrativas de Ceilândia e Taguatinga. Assim, os estudantes frequentam os centros de Ensino Fundamental (CEF) em um turno e, no outro, a Escola Parque da Ceilândia, tendo oportunidade de frequentar a educação integral.

O trabalho pedagógico na Escola Parque da Ceilândia também se alinha aos pressupostos teóricos do Currículo em Movimento da Educação Básica (GOVERNO..., 2014). As atividades são oferecidas na forma de oficinas. Os professores, em grupos de acordo com suas áreas de atuação, construíram a matriz curricular respeitando o currículo em movimento e as diretrizes de avaliação. Professores das áreas de educação física, artes, dança, música e informática fazem parte do seu quadro. Nesse contexto, o projeto da EPAT prevê a realização de oficinas nas áreas de educação física, artes, dança, música, literatura e tecnologia. Além da importância históricosocial, a escolha da EPAT se deu, principalmente, pela possibilidade de ter como participantes desta pesquisa crianças e adolescentes de diferentes unidades de ensino de duas regiões administrativas do Distrito Federal.

As crianças e os adolescentes participantes da pesquisa são estudantes da EPAT, matriculados na oficina de Tecnologia e Cultura, totalizando 21 estudantes entre 10 e 17 anos. Durante nossa participação nas aulas dessa oficina, desenvolvemos atividades com o software Pixton, tendo sido produzidas pelos participantes 33 histórias em quadrinhos, consideradas narrativas gráficas (EISNER, 2013). A partir delas, foram realizadas 21 entrevistas episódicas individuais, que configuraram narrativas orais. Flick destaca que, nesse tipo de entrevista, "dá-se uma atenção especial a situações ou a episódios nos quais o entrevistado tenha tido experiências que pareçam ser relevantes à questão do estudo” (2009, p. 172).

\section{O Tempo e o Espaço das TIC na Vida Cotidiana de Crianças e Adolescentes: "Não, Eu Não Vejo o Tempo Passar"}

Nos usos das TIC evidenciados nas narrativas das crianças e dos adolescentes, destacam-se as tecnologias digitais e, consequentemente, as mídias digitais. Iniciando a rota de aproximação ao cotidiano das crianças e dos adolescentes, buscamos dar materialidade à presença das mídias e tecnologias mostradas em suas narrativas, como importante ponto de partida para compreender suas apropriações. Nos quadrinhos extraídos da história do Téo (Fig.1), podemos identificar as mídias e tecnologias mais presentes no cotidiano dos participantes da pesquisa. $\mathrm{O}$ celular, muitas vezes acompanhado de fones de ouvido, o computador desktop ou notebook e a televisão se destacam como dispositivos de convergência das mais diversas mídias digitais. Já o tablet foi evidenciado mais como objeto de desejo e é menos presente no cotidiano dos participantes da pesquisa. Menos da metade afirmou possuir um.

Estudiosos do cotidiano (PAIS, 2003; BERGER; LUCKMANN, 2014) chamam atenção para a importância da dimensão espaço-tempo, pois é nela que a vida cotidiana se organiza. Se as TIC estão presentes, em variados usos, na vida cotidiana das crianças e dos adolescentes, como permeiam seus tempos e espaços? Observar as relações de uso do tempo e do espaço pode ser uma "rota" para o "momento" e o 
"lugar" da apropriação das TIC na vida cotidiana. Nas histórias em quadrinhos analisadas, as crianças e os adolescentes tendem a narrar sua vida cotidiana na ordem cronológica de um dia (ver Fig. 1). Ilustram, quadrinho a quadrinho, o turno escolar, a vida no lar, o tempo livre, a convivência com seus pares, com a família, entre tantas outras situações. As TIC são evidenciadas permeando esses tempos e espaços.

O computador - desktop ou notebook - é quase sempre representado no ambiente doméstico; nenhuma história em quadrinho ilustrou o uso do computador na escola. Esse fato chama atenção. Nas narrativas orais, somente quando questionados sobre essa questão, as crianças e adolescentes relatavam usos esporádicos ou afirmavam não ter acesso ao uso do computador na escola, exceto na EPAT, onde participavam da oficina de Tecnologia e Cultura, duas vezes por semana.

Já o celular é representado junto dos participantes, em qualquer lugar e momento do dia (Fig. 1). Todavia, com menor frequência no turno escolar. "Uma lei proíbe usar"; "Tem um aviso na parede da sala de aula"; "Só pode na hora do recreio, aí eu nem levo" são algumas das explicações encontradas em suas narrativas. "O uso das tecnologias, sobretudo no espaço da sala de aula, aparece como uma das mais visíveis e significativas subversões às regras institucionais exercidas pelas crianças”, argumentam Ferrarini, Queiroz e Salgado (2016, p. 1044). Outra maneira de burlar o controle, segundo as autoras, é a utilização de espaços como o banheiro da escola - como espaço de resistência, para acessar redes sociais e fazer selfies.

Existem também, em alguns casos, evidências de normas e orientações parentais sobre os riscos da Internet, sobre quando e quanto tempo usá-la, bem como a necessidade de permissão para sua utilização, especialmente, quando se trata do computador. Contudo, no uso do celular, essas normas e esses cuidados parecem se dissolver na mobilidade do dispositivo e na ubiquidade da Internet:

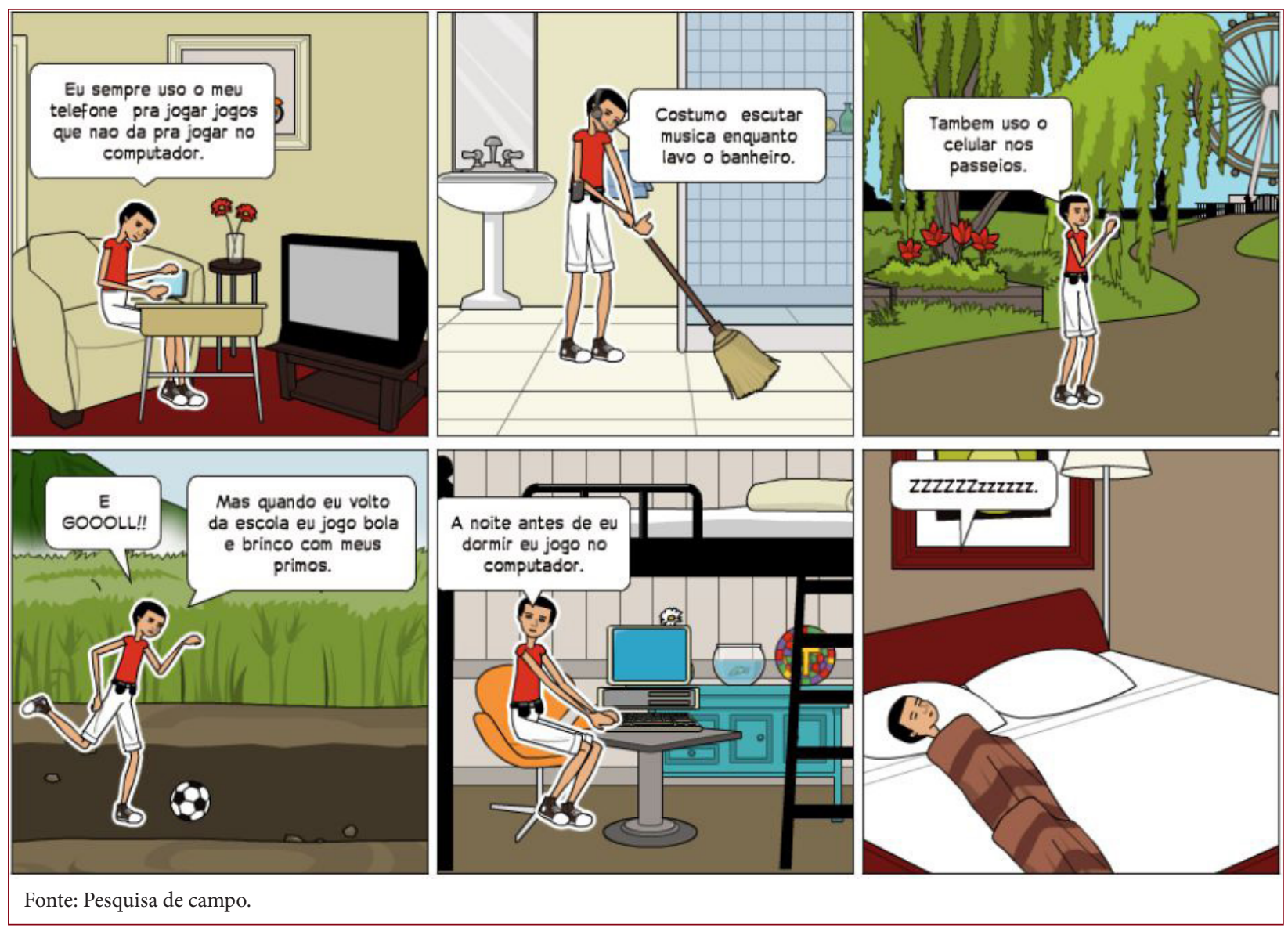

Figura 1. História em quadrinhos de Téo, 12 anos. 
Os adolescentes de hoje em dia são tipo assim... eles mexem no celular, depois mexem no computador, depois assiste... e vai dormir. A mãe deles manda eles dormir, só que, quando eles deitam na cama, eles começam a mexer no celular até umas três... quatro horas da manhã e depois vão dormir (Victor, 12 anos).

O relato se refere a um modo específico, porém recorrente, de burlar as normas ou orientações parentais. Nessa faixa etária, explica Corsaro (2011), são compartilhadas e refletidas em suas culturas de pares maneiras mais sutis e diretas de desafiar as autoridades adultas. De fato, várias histórias em quadrinhos ilustram o uso do celular na cama antes de dormir ou até mesmo do computador, quando esse fica no quarto da criança ou do adolescente. É interessante observar que algumas dessas histórias ilustram o início do dia com quadrinhos representando sono, cansaço demasiado, bem como falas tais como "Preguiça de ir pra escola" e "Todo santo dia tem aula”, sugerindo até mesmo um possível comprometimento do turno escolar em virtude da privação de sono.

$\mathrm{O}$ uso individualizado da Internet no celular parece se diluir em tempos e espaços para além dos limites acessíveis aos pais, dando certa autonomia para as crianças e os adolescentes em suas relações com as mídias e tecnologias digitais, já que nem sempre os pais teriam ciência desses momentos. Além disso, talvez fosse o caso da crítica colocada por Le Breton ao recuo da posição educativa dos mais velhos e, por isso, "as crianças deixaram de ser totalmente crianças, cada vez mais chamadas a decidir por elas mesmas com uma autonomia crescente [...] elas ficam muitas vezes sobrecarregadas com uma responsabilidade que não é da idade delas" (2017, p. 83). Outras formas identificadas de burlar ou "driblar" as regras dos adultos no ciberespaço também foram discutidas por pesquisadores - Sarmento e Barra (2006) e Becker (2013) -, como mentir a data de nascimento para criação de perfis em redes sociais, sites de jogos ou até mesmo criar perfis fake:

Pesquisadora: Mas o que você faz na maior parte do tempo?

Fico na Internet. É porque, assim... quando eu tô com a Internet, o tempo passa muito rápido. Aí eu começo a mexer na Internet umas duas horas da tarde. Quando eu paro de mexer na internet já é quase seis. [...] não, eu não vejo o tempo passar. Eu só jogo, jogo... quando eu percebo já é quase seis horas. Aí eu... eu percebo assim, quando eu tô jogando, aí o celular descarrega. [...] aí eu tomo banho, vou jantar, depois eu lavo a louça pra minha mãe. Depois eu deito na cama eu fico assistindo um pouco de televisão depois eu mexo no celular (Victor, 12 anos, grifos nossos).

Quando eu tô com celular, eu fico nele pra fazer trabalho, escutar música, mexer no YouTube, essas coisas (Julia, 13 anos, grifo nosso).

De fato, controlar o tempo de "ficar na Internet" emerge como um dos maiores desafios para essas crianças e esses adolescentes. Ao narrarem seus cotidianos, eles apontam claramente o excesso de tempo dedicado às atividades on-line, manifestam desconforto e conflitos e às vezes se autointitulam "viciados". Alguns demonstram estar cientes dos prejuízos e das consequências desses hábitos, mas outros parecem não se incomodar.

A Internet frequentemente é citada pelas crianças e pelos adolescentes como lugar real - "fico na Internet” -, como de fato é. Um lugar praticado, habitado, conforme a perspectiva de Certeau (1994), transformado em espaço pelas vivências e apropriações das pessoas. Um ciberespaço. Outras vezes, eles se referem à Internet como algo materializado ou personificado - "quando eu tô com a Internet". Também demonstram, semanticamente, maneiras próprias de se expressar sobre suas atividades com as mídias e tecnologias digitais. Por exemplo, o uso de termos como "ficar", "mexer", "fuçar" na Internet. Nenhum 
participante, criança ou adolescente, utilizou os termos "navegar", "acessar", "usar" a Internet, comumente usados por adultos. Observamos também que fazem críticas e reflexões (Fig. 2), as quais, muitas vezes, emergem como autodenúncias. É o caso do uso excessivo ou até mesmo compulsivo da Internet:

Hoje em dia, muitas pessoas são viciadas, dependem da tecnologia pra viver, as pessoas não pensam muito "ah... eu vivo por tecnologia". As pessoas estão muito ligadas à tecnologia mais pra um lado que facilita, deixando elas mais preguiçosas. É isso que eu acho ruim, porque é uma grande evolução, mas daqui a um tempo a gente vai começar a depender muito dela [...] eu queria que o pessoal... que o pessoal diminuísse o nível de... vício que tem. Só queria que o pessoal diminuísse o nível de vício que tem. [...] para eu poder parar com meu vício, porque eu também sou meio viciado em jogos (Paulo, 14 anos, grifos nossos).

Minha primeira experiência com tecnologia foi no computador [...] com seis ou sete anos. Desde então, eu fiquei viciada no computador... essas coisas. [...] eu fiquei tão viciada no computador que eu só fiquei de fone. Aí, eu fiquei me acostumando com fone toda a vida. A minha mãe pediu pra mim dar um tempo no celular e nas músicas também pra eu não ficar tão... [...] (Julia, 12 anos, grifos nossos).

Aí você não faz mais nada além daquilo, nem come direito. Você come super rápido pra continuar assistindo. Aí, depois... eu tô meio magro, depois da Internet. Eu tô meio magro depois da Internet (Vitor, 12 anos, grifo nosso).

Falar sobre esse assunto parece ser algo corriqueiro para eles. Praticamente em todas as narrativas das crianças e dos adolescentes, encontramos referências a si mesmo, amigos, familiares e até mesmo professores que não conseguem controlar o tempo de uso da Internet, não apenas em relação a jogos, mas nas suas infinitas possibilidades. Esse debate está presente na literatura, a partir de diferentes áreas do conhecimento, indicando que se trata de um fenômeno multidisciplinar. Ao discutirem relações, tensões e ressignificações dos cotidianos escolares e das tecnologias digitais móveis, Cordeiro e Bonilla (2017) apontam para a intensidade que tem marcado as relações entre gerações mais jovens e essas tecnologias. As autoras também destacam falas de alunos que fazem uso de termos como "viciado", usado em relação às tecnologias digitais - significando uma relação vigorosa e íntima -, e afirmam que se trata de um comportamento que toma conta do cotidiano das escolas e salas de aulas. A pesquisa TIC Kids Online Brasil traz um artigo dedicado à discussão dessa temática. Destacam os autores:

O uso excessivo e a não percepção da passagem do tempo; o desenvolvimento de quadros de abstinência, com alterações de humor e sentimentos de raiva e tristeza ou frustração; a tolerância e a necessidade de mais horas de uso, como mecanismo de recompensa; e as repercussões negativas, incluindo conflitos, isolamento social, fadiga e desempenho insatisfatório nos estudos ou no trabalho, são alguns dos sintomas que caracterizam a dependência (EISENSTEIN; SILVA, 2016, p. 120).

Procurando equilibrar a discussão, Lima (2011) se volta a uma abordagem detalhada do uso patológico dos jogos eletrônicos e outros aplicativos da Internet. Apresenta uma categorização dos jogos on-line (MATTAR, 2010), além de acrescentar considerações sobre benefícios do uso de jogos eletrônicos. Todavia, a autora destaca o papel fundamental dos pais, com diálogo e acompanhamento, para que esses jogos sejam usados de maneira equilibrada. Ao analisarmos essas relações, identificamos apropriações que convergem para um uso cada vez mais individualizado, em crescente ocupação dos cotidianos da infância, 


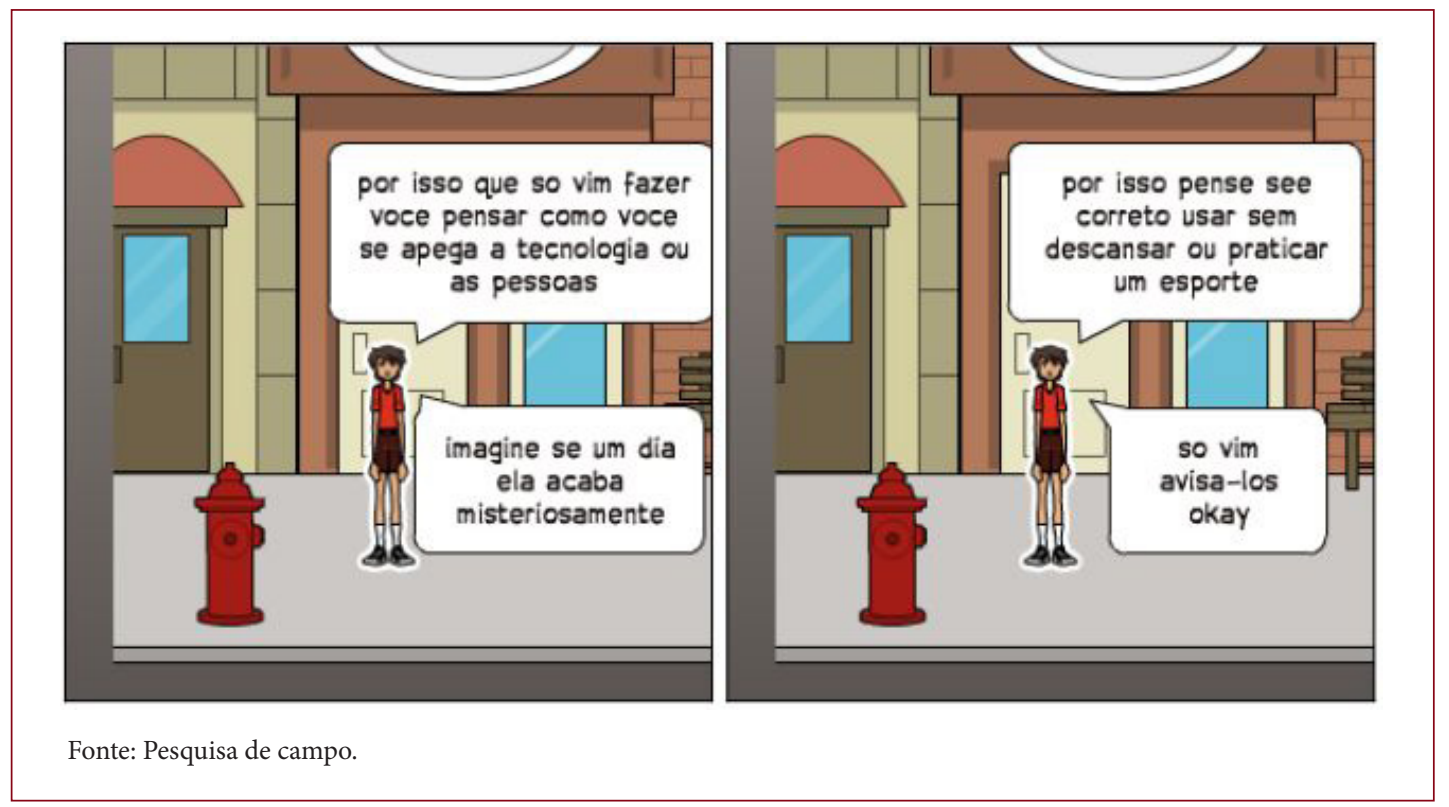

Figura 2. Quadrinhos extraídos da história em quadrinhos de Paulo, 14 anos.

tornando cada vez mais difícil manter o controle sobre o tempo de "ficar na Internet".

Nesse sentido, compreendemos que a convergência das TIC, somada à mobilidade em uma "rede ubíqua, envolvendo o usuário em um ambiente de acesso” (LEMOS, 2004, p. 29), representa mais do que avanços tecnológicos - fomenta mudanças na forma como as pessoas, e, principalmente, as crianças e os adolescentes se relacionam e seus modos de ser e viver em sociedade. Rainie e Wellman (2012) explicam que os relacionamentos se deslocaram de redes de lugar para lugar, para redes de pessoa para pessoa. Assim, se as redes de lugar para lugar possibilitaram à comunidade transcender as fronteiras locais, de igual modo as redes de pessoa para pessoa evidenciam como a comunidade transcendeu os limites do grupo. Segundo os autores, a unidade primária de conectividade agora é o indivíduo e não mais a família, o grupo de parentesco ou o trabalho. Dessa maneira, as pessoas são colocadas "no centro das redes pessoais que podem fornecer apoio, sociabilidade, informação e um senso de pertencimento. As pessoas se conectam pessoalmente via TIC. Suas atividades de networking mudam conforme a mudança de suas necessidades" (RAINIE; WELLMAN, 2012, p. 125, tradução nossa). Considerando o estudo dessas mudanças, os autores desenvolvem a ideia de “individualismo conectado". Nesse deslocamento, o ponto de conexão, que antes era o lugar, passou a ser o indivíduo. Cada pessoa conectada representa um nó da rede, cada pessoa representa um ponto de conexão.

\section{Considerações Finais}

Voltamos nosso olhar para as histórias narradas pelas crianças e pelos adolescentes na intenção de compreender as suas apropriações das TIC e como se relacionam com essas tecnologias na vida cotidiana. A análise evidencia, principalmente, a presença das mídias e das tecnologias digitais em diversos usos e em diferentes momentos do processo de apropriação, que se expandem na dimensão social. Ou seja, as crianças e os adolescentes da nossa pesquisa não possuem um "perfil" homogêneo de encantamento, sem dificuldades ou perturbações no que diz respeito às suas relações com toda a disponibilidade tecnológica da atual cultura digital. Muito pelo contrário, as crianças se distinguem umas das outras em suas apropriações, em seus modos de sentir e significar suas vivências, à semelhança do que afirmam Delgado e Müller sobre as crianças se 
distinguirem umas das outras "nos tempos, nos espaços, nas diversas formas de socialização, [...] tipos de brincadeiras, gostos, [...]. Partindo destas reflexões, é possível pensar sobre os significados que nós, adultos, atribuímos às crianças e às suas culturas" (2005, p. 167).

\section{Contribuições das Autoras}

Conceptualização: Tocantins GMO, Wiggers ID; Metodologia: Tocantins GMO, Wiggers ID; Redação: Tocantins GMO, Wiggers ID.

\section{REFERÊNCIAS}

BATISTA, C. L. Os conceitos de apropriação: contribuições à Ciência da Informação. Em Questão, Porto Alegre, v. 24, n. 2, p. 210-234, maio-ago. 2018. https://doi.org/10.19132/1808-5245242.210-234

BECKER, B. L. Brincando na Web: atividades lúdicas desenvolvidas por crianças de cinco a 12 anos na Internet. 2013. 1331 f. Dissertação (Mestrado em Psicologia) - Instituto de Psicologia, Universidade Federal da Bahia, Salvador, 2013.

BELLONI, M. L. O que é mídia-educação. Campinas: Autores Associados, 2005.

BELLONI, M. L. Os jovens e a Internet: representações, usos e apropriações. In: FANTIN, M.; GIRARDELLO, G. (orgs.). Liga, roda, clica: estudos em mídia, cultura e infância. Campinas: Papirus, 2008. p. 99-112.

BELLONI, M. L. Crianças e mídias no Brasil: cenários de mudança. Campinas: Papirus, 2010.

BERGER, P. L.; LUCKMANN, T. A construção social da realidade. 36. ed. Petrópolis: Vozes, 2014.

BUCKINGHAM, D. Crescer na era das mídias eletrônicas. São Paulo: Edições Loyola, 2007.

CERTEAU, M. A invenção do cotidiano. Petrópolis: Vozes, 1994. (Volume I: Artes de Fazer.)

CORDEIRO, S. F. N.; BONILLA, M. H. S. Cotidianos escolares e tecnologias digitais móveis: relações, tensões e ressignificações. In: REUNIÃO NACIONAL DA ANPED, 38., 2017, São Luís. Anais das reuniões nacionais da ANPEd, São Luíz, 2017, v. 1. p. 1-17.

CORSARO, W. A. Sociologia da infância. 2. ed. Porto Alegre: Artmed, 2011.

DELGADO, A. C. C.; MÜLLER, F. Em busca de metodologias investigativas com as crianças e suas culturas. Cadernos de Pesquisa, São Paulo, v. 35, n. 125, p. 161-179, maio-ago. 2005. https://doi.org/10.1590/ S0100-15742005000200009

EISENSTEIN, E.; SILVA, E. J. Crianças, adolescentes e o uso intensivo das tecnologias de informação e comunicação: desafios para a saúde. In: COMITÊ GESTOR DA INTERNET NO BRASIL. Pesquisa sobre o 
uso da Internet por crianças e adolescentes no Brasil: TIC Kids Online Brasil 2015. São Paulo: Cetic.br, 2016. EISNER, W. Narrativas gráficas. São Paulo: Devir, 2013.

FERRARINI, A. R. K.; QUEIROZ, F. R. O.; SALGADO, R. G. Infância e escola: Tempos e espaços de crianças. Educação e Realidade, Porto Alegre, v. 41, n. 4, p. 1027-1048, dez. 2016. https://doi. org/10.1590/2175-623660666

FLICK, U. Introdução à pesquisa qualitativa. 3. ed. Porto Alegre: Artmed, 2009.

GOVERNO DO DISTRITO FEDERAL. Secretaria de Estado de Educação. Currículo em Movimento do Distrito Federal: Educação Básica. Brasília, DF, 2014.

JAMES, A.; PROUT, A. (eds.). Constructing and reconstructing childhood: contemporany issues in the sociological study of childhood. Hapshire: The Falmer Press, 1990.

LE BRETON, D. Uma breve história da adolescência. Belo Horizonte: PUC Minas, 2017.

LEMOS, A. Cibercultura e mobilidade: a era da conexão. In: LEÃO, L. (org.). Derivas: cartografias do ciberespaço. São Paulo: Annablume/Senac, 2004.

LIMA, A. M. A. Cyberbullyling e outros riscos na Internet: despertando a atenção dos pais e professores. Rio de Janeiro: Wak, 2011.

MATTAR, J. Games em educação: como os nativos digitais aprendem. São Paulo: Pearson, 2010.

RAINIE, L.; WELLMAN, B. Networked: the new social operating system. Cambridge: MIT Press, 2012.

SANDHOLTZ, H.; RINGSTAFF, C.; DWYER, C. Ensinando com tecnologia: criando salas de aula centradas nos alunos. São Paulo: Artmed, 1997.

SARMENTO, M. J.; BARRA, S. M. Os saberes das crianças e as interações na rede. Zero-a-Seis, Florianópolis, v. 8, n. 14, p. 1-20, dez. 2006. ISSN 1980-4512. https:// doi.org/10.5007/\%x

SILVA, I. P.; MERCADO, L. P. L. Levantamento dos temas TIC e EAD na biblioteca virtual Educ@. Cadernos de Pesquisa, São Paulo, v. 45, n. 158, p. 970-988, dez. 2015. https://doi.org/10.1590/198053143367

PAIS, J. M. Vida cotidiana: enigmas e revelações. São Paulo: Cortez, 2003.

Recebido: 06 Jan. 2020

Aceito: 10 Jul. 2020

Editoras Associadas:

Adriana Laplane e Lucia Reily 